Rev. Saude puibl., S. Paulo

$15: 353-63$, 1981 .

\title{
DOENÇAS RESPIRATÓRIAS COMO CAUSA DE MORTE NO MUNICIPIO DE SAO PAULO, SP (BRASIL)
}

Ruy Laurenti *

LAURENTI, R. Doenças respiratórias como causa de morte no municipio de săo Paulo, SP (Brasil). Rev. Saùde públ., S. Paulo, 15:353-63, 1981.

RESUMO: $\mathbf{t}$ apresentada a mortalidade por doenças respiratorias no município de Săo Paulo (Brasil), destacando-se as infeccóes respiratórias agudas (IRA) e o que elas representam em relaçăo às doenças respiratórias crônicas (DRC). Os dados de mortalidade foram corrigidos por pesquisa com procura de informaçóes adicionais, o que permitiu comparar os dados oficiais de mortalidade e cs dados corrigidos. Concluiu-se que as estatisticas oficiais baseadas nos atestados de óbito não espelham a realidade quanto à magnitude das diferentes doenças respiratórias, superestimando as IRA e subestimando as DRC. Se a mesma distorção estiver ocorrendo em outras áreas do mundo, a importancia relativa das IRA na mortalidade por doenças respiratórias não apresenta a magnitude apontada por outros autores.

UNITERMOS: Danças respiratórias, S. Paulo, SP, Brasil. Mortalidade.

\section{INTRODUÇAO}

Nos últimos anos vem sendo dado destaque para as infecções respiratórias agudas (IRA) como causas de morte, sendo que Bulla e Hitze ${ }^{1}$ (1978) mostram alguns aspectos bastante interessantes, aos quais, aparentemente, não era dada a devida importância ou então não vinham sendo notados. Baseando-se nas informações sobre mortalidade que os paises membros da Organização Mundial da Saúde (OMS) enviaram a esse organismo e que foram publicadas no "World Health Statistics Annual", bem como informações publicadas no "Demographic Yearbook" das Nações Unidas, esses autores verificaram que as IRA constituem uma das principais causas de morbidade e mortalidade em muitos países. Trabalhando com dados de 88 paises de cinco continentes, com uma população de, aproximadamente, 1.200 .000 habitantes, mostraram que, no início da década de 70, ocorreram 666.726 mortes por IRA, sendo que as pneumonias (virais ou bacterianas) foram responsáveis por $75,5 \%$ desse total. A mortalidade por IRA representou $6,3 \%$ da mortalidade total, sendo mais alta na infância e nos velhos. Os autores ${ }^{1}$ chamam ainda a atençăo de que, para algumas áreas do mundo, a mortalidade por esse grupo de causas é extremamente alta, principalmente naqueles países considerados em desenvolvimento.

As IRA são constituídas pelas seguintes afecções, de etiologia viral ou bacteriana: rinofaringites, faringites, laringites, traqueites, bronquites, bronquiolites, influenza, pneu-

- Do Departamento de Epldemiologia da Faculda de de Saúde Pública da USP - Av. Dr. Arnaldo 715 - 01255 - Săo Paulo, SP - Brasil. 
LAURENTI, R. Doenças respiratórias como ca usa de morte no municiplo de São Paulo, SP (Brasil). Rev. Saúde públ., S. Paulo, 15: 35\&-63, 1981.

monias e broncopneumonias. Com exceção das pneumonias e broncopneumonias e.em menor grau a influenza e as bronquiolites agudas, as outras causas acima citadas nunca foram, a rigor, tomadas com a devida atenção como causas de morte. Isso pode ser devido, cm grande parte, ao fato de que as apresentações das estatisticas de mortalidade por causa sempre foram feitas pela chamada "Lista B", da Classificação Internacional de Doenças, na qual dentre as doenças do aparelho respiratório, somente apareciam a "Gripe ou Influenza (B31)", as "Pneumonias (B32)" e a "Bronquite, o Enfisema e a Asma (B33)". Uma análise mais específica da mortalidade por causas somente poderá ser feita se elas forem apresentadas pela lista detalhada da Classificação Internacional de Doenças ou mesmo por uma lista não tão resumida como é o caso da Lista A. Ambas as listas, A e B, serviam de modelos para apresentação de estatís- ticas de mortalidade enquanto vigente a 8a Revisão da Classificação Internacional de Doenças que vigorou até 1978, inclusive.

Bulla e Hitze ${ }^{1}$, enfocando a preponderância da mortalidade por IRA em relação às mortes por todas as doenças respiratórias, com os já citados dados dos 88 países, analisaram um total de 1.092.684 mortes por doenças respiratórias, de todas as idades, verificando que 666.726 delas, ou $61,0 \%$, eram por IRA e 425.958 , ou $39,0 \%$, por doenças respiratórias crônicas (DRC) (tuberculose, bronquite crônica ou não especificada, enfisema e asma). Esses autores, baseados nos dados que analisaram, apresentam várias tabelas mostrando o comportamento das causas de morte para vários grupos etários. A Tabela 1 mostra as percentagens das mortes por diferentes doenças respiratórias em relaçăo ao total dela e em relação ao total de mortes.

\section{T A B E L A 1}

Percentagem de mortes por diferentes doenças respiratórias em relação ao total de mortes por doenças respiratórias e em relação ao total de mortes por todas as causas em todas as idades.

\begin{tabular}{|c|c|c|c|c|c|}
\hline \multirow[t]{2}{*}{ Doenças } & \multicolumn{3}{|c|}{$\begin{array}{c}\text { Infecções Respiratórias Agudas } \\
\text { (IRA) }\end{array}$} & \multicolumn{2}{|c|}{$\begin{array}{c}\text { Doenças Respiratórias Crônicas } \\
\text { (DRC) }\end{array}$} \\
\hline & $\begin{array}{l}\text { Infecçóes agudas } \\
\text { de vias aéreas } \\
\text { superiores }\end{array}$ & Infl. & Pneum. & $\begin{array}{l}\text { Thiberculose } \\
\text { Ap. Respiratório }\end{array}$ & $\begin{array}{l}\text { Brônquite crónica, } \\
\text { asma e enfisema }\end{array}$ \\
\hline \multirow{2}{*}{$\begin{array}{l}\text { \% em relação ao total de } \\
\text { mortes por doenças } \\
\text { respiratórias }\end{array}$} & 9,6 & 5,4 & 46,0 & 11,1 & 27,9 \\
\hline & \multicolumn{3}{|c|}{61.0} & \multicolumn{2}{|c|}{39,0} \\
\hline \multirow{2}{*}{$\begin{array}{l}\% \text { em relaçăo ao total de } \\
\text { mortes por todas as causas }\end{array}$} & 0.9 & 0,6 & 4,8 & 1,1 & 2,9 \\
\hline & \multicolumn{3}{|c|}{6,3} & \multicolumn{2}{|c|}{4,0} \\
\hline
\end{tabular}

Fonte: Bulla e Hitze I

Consideramos o trabalho de Bulla e Hitze 1 bastante importante por chamar a atenção para as IRA. Temos, porém, algumas dúvidas quanto à magnitude real do problema $e$ isso advém pela vivência que temos tido em estudos de mortalidade baseados em diagnósticos registrados nos atestados de óbitos. Há vários anos temos participado em "estudos especiais de mortalidade", onde tem sido possível verificar que, pelo menos 
LAURENTI, R. Doenças respiratórias como causa de morte no munićpíio de São Paulo, SP (Brasil). Rev. Saúde pübl., S. Paulo, 15:35;-63, 1981.

entre nós, alguns diagnósticos não correspondem a realidade. Assim, por exemplo. as pneumonias são sempre superenumeradas como causa básica de morte nos atestados de óbito, os quais, entre nós não espelham com boa fidedignidade as causas básicas da morte 2,4. Os estudos que temos participado tem analisado a mortalidade de adultos de 15 a 74 anos 7,3 , crianças menores de 5 anos 5,8 e óbitos hospitalares de todas as idades 6 .

No estudo de mortalidade de adultos", no município de São Paulo, verificou-se que as pneumonias eram apontadas pelos médicos como causa básica da morte, nos atestados de óbito, $35 \%$ a mais do que deveriam ser. Em outras áreas que participaram do estudo isso também foi ubservado, como Bogotá/Colombia (17,5\%); Bristol/ /Inglaterra (133\%); Cali/Colombia (46\%); Caracas/Venezuela $(101 \%)$; Cidade da Guatemala $(141 \%)$ : La Plata/Argentina $(4,5 \%)$; Lima/Perú $(48 \%)$; Cidade do México (37\%); Ribeirão Preto/Brasil (50\%) San Francisco/USA (81\%) e Santiago/ Chile $(45 \%)$.

$\mathrm{Na}$ "Investigação Interamericana de Mortalidade na Infância" " , realizada no período $1968 / 70$, em várias cidades das Américas, inclusive uma nos Estados Unidos (San Francisco) e outra no Canadá (Sherbrooke), verificou-se as mesmas discordâncias entre o que deveria ser e o que era na realidade declarado como causa básica de morte, nos atestados de óbito, para crianças menores de 5 anos. Mais recentemente, em 1974/75, analisamos novamente uma amostra de óbitos, na cidade de São Paulo, de adultos de 15 a 74 anos; ainda continuaram a haver erros quanto à declaração de causa básica da morte ${ }^{3}$.

Os resultados mostrados nessas pesquisas nos levaram a questionar se realmente as doenças respiratórias como causa de morte têm o comportamento descrito no trabalho de Bulla e Hitze ${ }^{1}$. Aliás, é preciso mencionar que esses autores 1 enfatisam que os dados sobre mortalidade por IRA devem ser usados com cautela, por várias razóes, apontando 6 possibilidades de erro e sobre isso afirmam "althoug, in the light of previously mentioned limitations, this review is necessarily restricted and superficial in its coverage of certain aspects, it may serve as a prerequisite for a critical appraisal of what is known to date about the problem, and for the tentative indentification of potential "problem areas" in the world". Estamos inteiramente de acordo com essa posição dos autores.

Como dispunhamos dos questionários $\mathrm{e}$ de numerosas tabulações referentes as duas investigações especiais de mortalidade, uma para menores de 5 anos 8 e outra para adultos de 15 a 74 anos ${ }^{3}$, resolvemos analisar o comportamento das doenças respitórias como causa de morte, situando o papel das IRA e DRC, bem como comparar na amostra os dados baseados nos atestados de óbito com aqueles procedentes de pesquisa, com enrevista, para correção das informações.

\section{MATERIAL E METODOS}

Para as mortes de menores de 5 anos foi utilizada uma amostra de 4.312 óbitos, sendo 3.788 de menores de um ano e $\mathbf{5 2 4}$ de um a 4 anos. Essa amostra correspondeu àquela estudada na área do município de São Paulo e que fez parte do projeto da "Investigação Interamericana de Mortalidade na Infância 5,8 , cujos óbitos ocorreram de 1 o de junho de 1968 a 31 de maio de 1970. Para cada caso era feita entrevista na residência para coleta de informações, bem como entrevista junto a médicos, hospitais, clinicas, que cuidaram do caso, bem como eram utilizados laudos de autópsias, exames, entre outros. Um dos objetivos era conhecer as verdadeiras causas básicas e associadas de morte e compará-las com as informaçōes obtidas somente por meio dos atestados de óbito. A descrição mais pormenorizada da metodologia empregada encontra-se em Puffer e Serrano 8.

Para as mortes de 15 a 74 anos foi utilizada uma amostra de 2.743 casos, de resi- 
LAURENTI, R. Doenças respiratórias como causa de morte no município de Săo Paulo, SP (Brasil). Rev. Saúde públ., S. Paulo, 15:35:̈-63, 1981.

dentes na mesma área que os menores de 5 anos, no periodo de 19 de outubro de 1974 a 30 de setembro de 1975 . Também para esses casos se estudou pormenorizadamente cada óbito com entrevistas com famílias, médicos, hospitais, clínicas, entre outros, procurando-se conhecer as verdadeiras causas básicas e associadas de morte. Em trabalho de Guimarães e col. ${ }^{3}$ encontra-se descrição completa da metodologia utilizada.

\section{RESULTADOS E COMENTARIOS}

$\mathrm{Na}$ Tabela 2 estão os resultados mostrando o comportamento das doenças respiratórias nos grupos etários menores de um ano, um a 4 anos e 15 a 74 anos. Essa Tabela procura apresentar os resultados de uma maneira semelhante a do trabalho de Bulla e Hitze 1, a qual encontra-se reproduzida na Tabela 1.

- Para os menores de 1 ano, dentre as mortes por doenças respiratórias, existe um grande predominio das IRA $(97,4 \%)$ em relação as DRC $(2,3 \%)$. Nesse grupo etário não se observaram grandes diferenças entre os resultados da pesquisa e aqueles procedentes dos atestados de óbito, quanto à proporção total de IRA e DRC, porém, verificaram-se diferenças nos seus diversos componentes. Assim, o conjunto "jnfecções das vias aéreas superiores (categorias

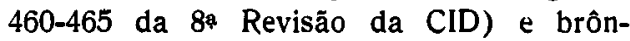
quite e bronquiolites agudas (categoria 466)" que pelos resultados da pesquisa foram responsáveis por $13,6 \%$ das doenças respiratórias, pelos atestados de óbito isso ocorria em $8,3 \%$, isto é, houve um aumento da importância relativa de 1,63 vezes. Dentre as DRC deve-se destacar que também o agrupamento "Bronquite, Enfisema e Asma (categorias 490-493)", pelos resultados da pesquisa foi mais freqüente $(1,5 \%)$ que pelos resultados baseados nos atestados de óbito $(0,9 \%)$. As "Pneumonias (categorias 480-486)" tiveram, pela pesquisa, sua importância relativa, discretamente diminuída.
No grupo etário um a 4 anos os resultados da pesquisa mostraram diferenças bem maiores em relação aos dados retirados dos atestados de óbito, segundo os quais as IRA foram responsáveis por $83,9 \%$ das mortes por doenças respiratórias e as DRC por $15,5 \%$. A pesquisa mostrou, porém, que esses valores, na realidade, correspondiam a $\mathbf{7 6 , 7 \%}$ e $\mathbf{2 2 , 5 \%}$. Neste grupo etário, como se observa na Tabela 2 , as pneumonias estavam superenumeradas nos atestados de óbito, bem como a influenza. Por outro lado, a pesquisa mostrou um aumento da importância relativa de, aproximadamente, 4 vezes no conjunto "infecções agudas de vias aéreas superiores e brônquite e bronquiolites agudas". Aumentou também a importância dos dois grupos de DRC aqui considerados: "Tuberculose do aparelho respiratório (categorias 010-012)" e "Bronquite, Enfisema e Asma (categoria 490-493)". Mesmo com as mudanças observadas as IRA continuaram com um papel de destaque na mortalidade por doenças respiratórias.

A grande diferença, porém, entre os resultados da pesquisa e os dos atestados de óbito, é o que se verificou no grupo etário de 15 a 74 anos. As estatísticas provenientes dos atestados de óbito evidenciavam que, mesmo nesse grupo etário, as IRA eram mais importantes do que as DRC, $54,5 \%$ e $32,8 \%$, respectivamente. A pesquisa mostrou, porém, que pelo menos na amostra estudada, isso não acorreu, pois as DRC eram muito mais importantes que as IRA, havendo uma completa inversão como se verifica na Tabela 2.

Nesse grupo etário os atestados de óbito apresentam muito mais freqüentemente as pneumonias e broncopneumonias como causa básica de morte do que deveriam apresentar. Revendo os históricos clínicos dos casos, pode-se afirmar que, para a quase totalidade das vezes, existia, na realidade, uma pneumonia ou broncopneumonia, porém, essas afecções não eram a causa básica, mas sim causas consequienciais à básica, geralmente causa terminal. Na amostra de 2.743 mortes de 15 a 74 anos, pelos 
T A B E I 2

Percentagem de mortes, segundo dados da pesquisa (P) e dos atestajos de óbito (AO), por diferentes doenças respiratórias $e m$ relaçáo ao total de mortes por doenças respiratórias e em relação ao total de mortes por todas as causas nos grupos etários menores de um ano (1968/1970), I m a 4 anos (1968/1970 e 15 a 74 anos (1974/1975). Município de Săo Paulo

(19 Distrito/Capital).

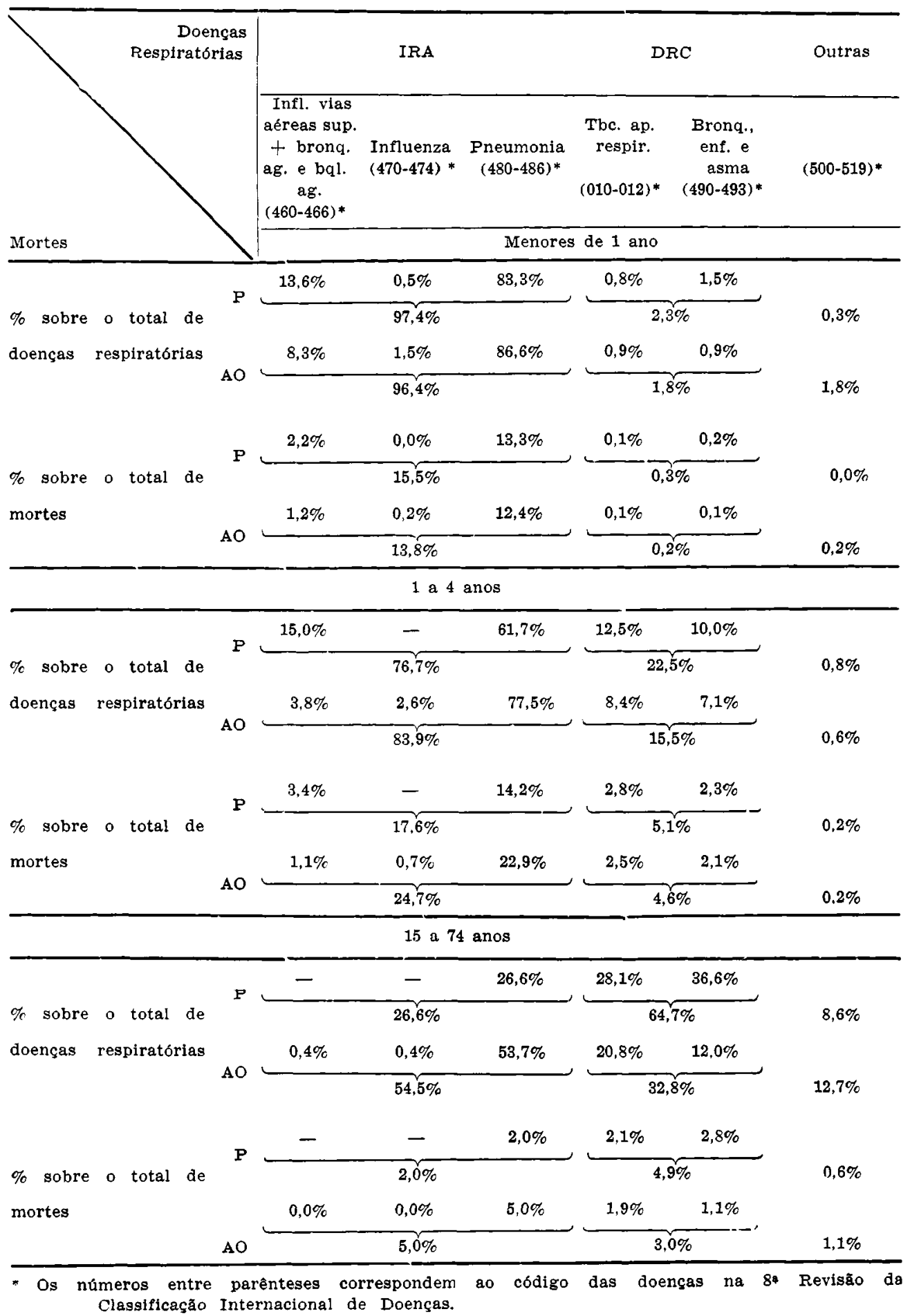


LAURENTI, R. Doenças respiratórias como causo de morte no município de São Paulo, SP (Brasil). Rev. Saúde públ., S. Paulo, 15:353-63, 1981.

T A B E L A 3

Doenças respiratórias como causa básica de morte segundo os atestados de óbito e a pesquisa em uma amostra de 2.743 mortes de 15 a 74 anos. M: nicipio de São Paulo (10 Distrito/Capital), 1974/75

\begin{tabular}{|c|c|c|c|c|c|c|c|c|}
\hline $\begin{array}{l}\text { Pesquitsa } \\
\text { Atestado } \\
\text { de obito }\end{array}$ & $\mid \begin{array}{c}\text { Inf. v.a. } \\
\text { sup. }+ \text { bq. } \\
\text { ag. e bql. } \\
\text { ag. } \\
(460-466) *\end{array}$ & $\begin{array}{c}\text { Inf. } \\
(470-474)\end{array}$ & $\begin{array}{c}\text { Pneum. } \\
(480-486) *\end{array}$ & $\begin{array}{c}\text { Tbc. } \\
(010-012) *\end{array}$ & $\begin{array}{c}\text { Bronq., } \\
\text { enfisema e } \\
\text { asma } \\
(490-493) *\end{array}$ & $\begin{array}{c}\text { Outras } \\
\text { doenças } \\
\text { resp. } \\
(500-519)\end{array}$ & $\begin{array}{c}\text { Todas as } \\
\text { outras } \\
\text { doenças }\end{array}$ & Total \\
\hline $\begin{array}{l}\text { Inf. v.a. sup. } \\
+ \text { bq. ag. e } \\
\text { bql. ag. } \\
(460-466) *\end{array}$ & - & - & - & - & - & - & 1 & 1 \\
\hline $\begin{array}{c}\text { Infl. } \\
(470-474)^{*}\end{array}$ & 一 & - & - & 1 & - & - & - & 1 \\
\hline $\begin{array}{l}\text { Pneum. } \\
(480-486) \text { * }\end{array}$ & - & - & 50 & 1 & 10 & 2 & 76 & 139 \\
\hline $\begin{array}{c}\text { Tbc. } \\
(010-012) *\end{array}$ & - & - & - & 46 & - & 1 & 7 & 54 \\
\hline $\begin{array}{l}\text { Bronq., enfi- } \\
\text { sema e asma } \\
(490-493) *\end{array}$ & - & - & - & - & 26 & 1 & 4 & 31 \\
\hline $\begin{array}{l}\text { Outras doen_ } \\
\text { cas resp. } \\
\text { (500-519)* }\end{array}$ & - & - & - & 2 & 4 & 11 & 16 & 33 \\
\hline $\begin{array}{l}\text { Todas as ou- } \\
\text { tras doenças }\end{array}$ & - & - & 6 & 9 & 37 & 4 & 2.428 & 2.483 \\
\hline Total & - & - & 56 & 59 & 77 & 19 & 2.532 & 2.743 \\
\hline
\end{tabular}

atestados de óbito haviam 139 casos em que as pneumonias ou broncopneumonias foram selecionadas como causa básica, enquanto a pesquisa mostrou que isso ocorria em apenas 56 vezes. As doenças respiratórias, como causa básica de morte, selecionadas a partir dos atestados de óbito e a partir da pesquisa, com as concordâncias e discordâncias, estão expressas na Tabela 3. Por meio dessa Tabela é que se calcularam todos os valores relativos (\%) contidos na Tabela 2, para o grupo etário de 15 a 74 anos. Para os dois outros grupos aqui analisados também forma feitas Tabelas semelhantes a Tabela 3 , porém não serão aqui apresentadas. Pela Tabela 3, das 139 vezes em que pelos atestados de óbito uma pneumonia ou broncopneumonia era selecionada como causa básica de morte, isso, na realidade, segundo a pesquisa, somente deveria ter ocorrido em 50 vezes, ou $35,9 \%$. Em 13 vezes, ou 9,3\%, a causa hásica era outra doença respiratória e em 76 vezes, ou $54,7 \%$, eram outras doenças não respiratórias. Outra grande diferença verificada foi quanto ao agrupamento "bronquite, enfisema e asma" que na pesquisa ocorreu 77 vezes como causa básica, ao passo que pelos atestados ocorreu apenas 31 vezes.

São essas diferenças, observadas entre os resultados de estatísticas de mortalidade 
LAURENTI, R. Doenças respiratórias como causa de morte no município de São Paulo, SP (Brasil). Rev. Saúde pübl., S. Paulo, 15: 353-63, 1981.

"oficiais", isto é, baseadas nos atestados de óbito e os dados corrigidos por pesquisa, que nos levam a não aceitar totalmente os resultados apresentados por Bulla $\mathrm{e}$ Hitze 1. Poder-se-ia argumentar que o que está aqui descrito é específico para São Paulo e não ocorreria em outras áreas. Recorrendo-se, porém, aos resultados das pesquisas publicadas por Puffer e Griffith 7 e Puffer e Serrano ${ }^{8}$ verifica-se que isso também ocorre em outras áreas, não somente latino-americanas mas também norte-americanas e inclusive na Europa.

Não restam dúvidas que as IRA são, como causa de morte, as mais importantes doenças respiratórias nas idades inferiores a 5 anos, porém em adultos de 15 a 74 anos, pelo menos nos nossos resultados, isso não ocorre, ainda que as estatísticas baseadas nos atestados de óbito assim 0 mostre.

Quanto aos coeficientes de mortalidade por IRA e DRC nos grupos etários menores de um ano, um a 4 anos e 15 a 74 anos (Tabela 4) eles aparecem, comparativamente, segundo dados obtidos pela pesquisa e a partir dos atestados de óbito.

Como se observa pelos resultados expostos na Tabela 4 os coeficientes de mortalidade por IRA são superestimados, nos dados provenientes dos atestados de óbito, nos gupos etários de um a 4 anos e de 15 a 74 anos, principalmente no primeiro deles (41\% a mais). Isso somente não ocorreu no grupo etário menor de um ano, onde a pesquisa mostrou ser maior a mortalidade por IRA do que indicavam os atestados de óbito (13\% a mais). Com as DRC acontece o oposto, isto é, os coeficientes de mortalidade, quando calculados a partir dos atestados de óbito, são menores do que quando calculados a partir dos dados da pesquisa. Assim, os coeficientes calculados pelos resultados da pesquisa foram, no grupo etário menor de 1 ano, $40 \%$ maior, no grupo 1 a 4 anos, $16 \%$ maior, e para 0 de 15 a 74 anos, $59 \%$ maior. Realmente, como já havia sido visto por meio da mortalidade proporcional (Tabela 2) a mortalidade por DRC é bastante subestimada nas estatisticas oficiais de mortalidade, o que faz crescer a importância relativa das IRA. Estas por sua vez são superestimadas nas estatisticas oficiais (no presente estudo isso não ocorreu apenas nos menores de 1 ano), 0 que as fazem sobressair ainda mais.

Bulla e Hitze ${ }^{1}$ estimaram os coeficientes de mortalidade por IRA baseando-se em

TA B E L A 4

Coeficientes de mortalidade por IRA* e DRC** segundo dados da Pesquisa (P) e de Atestados de óbito ( $A O)$, para menores de um ano (1968/70), um a 4 anos $(1968 / 70)$ e de 15 a 74 anos (1974/75). Muntcipio de São Paulo (19 Distrito/Capital) Coeficientes por 100.000 .

\begin{tabular}{|c|c|c|c|c|}
\hline \multirow[b]{2}{*}{ Idade } & \multicolumn{2}{|c|}{ IRA } & \multicolumn{2}{|c|}{ DRC } \\
\hline & $\mathbf{P}$ & AO & $\mathbf{P}$ & AO \\
\hline Menores de 1 ano & $1.019,6$ & 900,9 & 24,1 & 17,2 \\
\hline 1 a 4 anos & 48,8 & 69,0 & 14,3 & 12,3 \\
\hline 15 a 74 anos & 11,7 & 29,7 & 28,6 & 17,9 \\
\hline
\end{tabular}

* IRA - Infecções respiratórias agudas.

** DRC - Doenças respiratórias crônicas. 
LAURENTI, R. Doenças respiratórias como causa de morte no município de São Paulo, SP (Brasil). Rev. Saúde públ., S. Paulo, 15:35?-63, 1981.

dados dos 88 paises dos cinco continentes. Comparando-se com os nossos resultados verifica-se que para os menores de um ano a mortalidade por IRA é inferior a observada na América Central $(1.495,0$ por $100.000)$, África $(1.454,1$ por 100.000$)$, paises em desenvolvimento da Ásia (1.242,4 por 100.000 ) e mesmo na América Latina $(1.110,5$ por 100.000$)$. A mortalidade, ainda para o grupo menor de um ano, porém, é muito maior, em São Paulo, relativamente aos paises desenvolvidos.

No grupo de um a 4 anos, a mortalidade por IRA em São Paulo é muito menor que a calculada para a África $(467,0$ por 100.000), paises em desenvolvimento da Ásia $(204,1$ por 100.000$)$, América Central $(149,3$ por 100.000$)$ e América do Sul (112,6 por 100.000$)$. As mais baixas mortalidades, nesse grupo etário, encontradas por Bulla e Hitze 1, foram: América do Norte e Oceania (Austrália e Nova Zelândia) respectivamente 8,0 e 8,2 por 100.000 . Como se verifica, são bastante inferiores à mortalidade em São Paulo (Tabela 4).

Para os adultos, Bulla e Hitze 1 somente apresentam os coeficientes para as idades de 55-64 e 65-74 anos *. Para comparar apresenta-se na Tabela 5 o grupo etário de 15 a 74 anos separado em subgrupos, verificando-se que os coeficientes em São Paulo, para aqueles dois subgrupos, são bastante inferiores aos de, praticamente, todos os paises - desenvolvidos e em desenvolvimento - exceto para a Austrália e Nova Zelândia, e isso apenas nas idades de 65-74 anos. Na Tabela 5 os coeficientes foram calculados somente com dados da pesquisa, porém, mesmo calculando-se com dados dos atestados de óbito, São Paulo continuaria tendo coeficientes mais baixos. Na Tabela 5 estão apresentados também os coeficientes de mortalidade por DRC, os quais, excetuando-se as idades de 15 a 24 anos, são sempre superiores àqueles por IRA. Como se pode observar na Tabela 5, a morta- lidade por DRC e por IRA aumenta com a idade, porém esse aumento é muito maior para as DRC. Assim, da idade de 15-24 anos para 65-74 anos, a mortalidade por DRC aumentou 50,6 vezes e a mortalidade por IRA aumentou 14,5 vezes.

Ainda na Tabela 5 colocamos os dados para os menores de 5 anos, os quais, juntamente com aqueles para as idades 15 a 74 anos, pode oferecer uma visão mais completa do quadro da mortalidade por doenças respiratórias, mesmo não se dispondo de informaçōes para as idades de 5 a 14 anos e maiores de 74 anos. Fica bastante clara a importância das IRA na mortalidade em menores de 5 anos; essa importância diminui bastante a partir dos 15 anos, porém, ainda no grupo de 15 a 24 anos ela representa quase a metade das mortes dentre as doenças respiratórias. Tudo leva a crer que no grupo etário de 5 a 14 anos as IRA são mais importantes que as DRC.

Outro aspecto que pode ser destacado na Tabela 5 é o comportamento dos coeficientes de mortalidade e a mortalidade proporcional nos diferentes grupos etários de 15 a 74 anos. Como se observa, mesmo sendo os coeficientes de mortalidade por IRA bastante inferiores àqueles por DRC, não se pode, a rigor, considerar que a mortalidade proporcional seja pequena. De fato, exceto no grupo de 55 a 64 anos onde ela representa $14,3 \%$, em todos os outros grupos se situa acima de $20,0 \%$ o que mostra sua importância relativa como causa de morte dentre as doenças respiratórias. Comparando-se a mortalidade proporcional por IRA e DRC, por meio dos dados corrigidos por pesquisas para as idades em que se dispōe desses dados, é possivel supor que, para a população total, as IRA são responsáveis por valores em torno de $60 \%$. A análise da Tabela 5 nos sugere tal afirmação.

A importância das doenças respiratótias como causa de morte pode ser enfocada de

* Para o grupo etário de 55-64 anos os coeficientes variaram de 23,1 a 100,2 por 100.000 e para 65-74 anos de 62.5 a 279.3 por 100.000 . 
LAURENTI, R. Doenças respiratórias como causa de morte no municipio de São Paulo, SP (Brasil), Rev. Saúde públ., S. Paulo, 15:35:3-63, 1981.

T A B E L A 5

\begin{tabular}{|c|c|c|c|c|c|c|}
\hline Menores de 1 ano & 97,4 & 1019,6 & 2,3 & 24,1 & 0.3 & 3.1 \\
\hline 1 a 4 anos & 76,7 & 48,8 & 22,5 & 14,3 & 0,8 & 0,5 \\
\hline 0 a 4 & 94,0 & 281,0 & 5,6 & 16,7 & 0,4 & 1,1 \\
\hline 15 a 24 & 46,7 & 4,8 & 33,3 & 3,4 & 20,0 & 2,0 \\
\hline 25 a 34 & 20,0 & 4,3 & 72,0 & 15,3 & 8,0 & 1,2 \\
\hline 35 a 44 & 35,7 & 10,9 & 56,6 & 16,5 & 10.7 & 3.2 \\
\hline 45 a 54 & 28,9 & 20,4 & 62,2 & 43,9 & 8,9 & 6,2 \\
\hline 55 a 64 & 14,3 & 15,8 & 78,6 & 87,4 & 7,1 & 7,9 \\
\hline 65 \&. 74 & 27,3 & 69,8 & 67,3 & 172,3 & 5,4 & 13,9 \\
\hline 15 a 74 & 26,6 & 11,7 & 64.7 & 28,6 & 8,7 & 3,7 \\
\hline
\end{tabular}

outra maneira que não a tradicional análise por causa básica. Assim, a análise de mortalidade por causa múltipla pode fornecer muito mais informações. Nas duas pesquisas que estamos aqui comentando foi utilizado esse método de análise, porém os resultados sob esse ponto de vista não serão no momento apresentados. Vamos nos ater aos resultados de outro estudo, onde se analisaram os óbitos de todas as idades ocorridos em hospitais da cidade de São Paulo (70\% do total), no período de março 1971 a fevereiro $1977 \%$, segundo a mesma metodologia das outras duas pesquisas; da mesma maneira, as causas de morte foram analisadas segundo causa básica e segundo causa múltipla. Verificou-se que as IRA, como causa básica de morte nos atestados, representam $85,4 \%$ das mortes por doenças respiratórias, enquanto a pesquisa revelou ser esse valor igual a $70,3 \%$. Como causa múltipla de morte as IRA, nos atestados originais representavam $89,3 \%$ de todos os diagnós- ticos registrados; conseguindo-se, pela pesquisa, esse valor diminuir um pouco, passando a $84,0 \%$.

Esses resultados mostram que as IRA são de fato importantes, ainda que, no caso de São Paulo, as duas pesquisas revelaram, segundo causa básica de morte, que os atestados originais superestimam a magnitude, principalmente nos adultos.

$O$ que tentamos fazer neste trabalho $\dot{e}$ mostrar que, embora as IRA sejam bastante importantes como causas básicas de morte, principalmente nas idades mais jovens, é preciso analisar com certa cautela os dados baseados em atestados de óbito. Isso, nas amostras aqui analisadas, ficou muito claro, principalmente no grupo etário de 15 a 74 anos onde as IRA, pelos atestados de óbito, eram responsáveis por $54,4 \%$ da mortalidade por doenças respiratórias e as DRC por apenas $32,8 \%$. Ao se corrigir os dados por meio da pesquisa esses valores se inverteram (IRA: 26,2\% e DRC: $64,7 \%$ ). 
LAURENTI, R. Doenças respiratórias como causa de morte no município de São Paulo, SP

(Brasil). Rev. Saúde pübl., S. Paulo, 15:353-63, 1981.

No grupo etário de um a 4 anos também ocorreram mudanças, ainda que sem observar uma inversão; porém é preciso destacar que as DRC passaram de $15,5 \%$ (atestados de óbito) para $22,5 \%$ (pesquisa). Somente nos menores de um ano é que a pesquisa evidenciou ser discretamente maior a importância das IRA, porém, também as DRC aumentaram de importância (de $1,8 \%$ para $2,3 \%)$

Bulla e Hitze ${ }^{1}$ também chamam a atenção para a influenza, mostrando que em alguns países ela foi responsável por até 13 a $16 \%$ da mortalidade por IRA. Para São Paulo isso não foi observado, visto que apenas no grupo etário menor de um ano a pesquisa mostrou ser ela responsável por $0,5 \%$ das IRA, ainda que pelos atestados de óbito isso tivesse ocorrido nos menores de um ano $(1,5 \%)$, um a 4 anos $(2,6 \%)$ e 15 a 74 anos $(0,4 \%)$. Esses dados indicam que os médicos, algumas vezes, ao preencher os atestados de óbito informaram essa doença como causa básica, quando na realidade isso não existia. É preciso lembrar, por outro lado, que a comparação entre a mortalidade por influenza em diferentes áreas e anos depende não somente da qualidade do diagnóstico como também da existência ou não de um periodo epidêmico.

Não se pode esquecer alguns aspectos que precisam ser comentados quando fazemos comparações como aqui feitas. Assim, pode-se questionar se nos paises cujos dados foram utilizados por Bulla e Hitze ${ }^{1}$ os atestados de óbito também não informam corretamente as verdadeiras causas de morte, como ocorre em São Paulo, no caso, especificamente com as doenças respiratórias. Já na introdução desta apresentação comentamos que em uma pesquisa feita $\mathrm{em}$ $1962 / 64$ r isso ocorria em outras 11 cidades (9 latino-americanas, uma norte-americana e uma inglesa), onde, em algumas delas, as pneumonias eram informadas nos atestados de óbito mais que o dobro do que deveriam ser; isto é, as causas básicas eram outras $t$ os médicos declaravam pneumonias nos atestados. Tal fato, evidentemente, inflacionam as IRA como causa básica de morte, acrescentando-se, também, que as DRC eram informadas menos vezes. Esses fatos que foram descritos para adultos de 15 a 74 anos, em 1962/64, também foram verificados para menores de 5 anos em várias cidades da América Latina e duas da América do Norte ${ }^{8}$, em 1968/70. Esses achados nos levam a suspeitar que o quadro apresentado por Bulla e Hitze ${ }^{1}$, sobre o panorama mundial da mortalidade por doenças respiratórias, poderá não ser totalmente exato quanto à real magnitude da mortalidade por IRA. Essas, ainda que bastante importantes, não teriam os níveis apresentados por aqueles autores. Por outro lado, a análise por causa múltipla de morte, em São Paulo, dá a devida importância ao problema.

\section{CONCLUSOES}

No município de São Paulo as doenças respiratórias são importantes causas de morte, destacando-se as infecções respiratórias agudas em menores de 5 anos. A análise da mortalidade por doenças respiratórias em três grupos etários (menores de um ano, um a 4 anos e 15 a 74 anos) permitiu concluir que as estatísticas oficiais baseadas nos atestados de óbito náo espelham a realidade quanto à magnitude dos diferentes tipos destas doenças. Nos três grupos etários estudados as estísticas oficiais subestimaram a mortalidade por doenças respiratórias crônicas e, excetuando-se os menores de um ano, superestimaram as doenças respiratórias agudas. Se a mesma distorção estiver ocorrendo em outras áreas do mundo, a importância relativa das infecções respiratórias agudas na mortalidade por doenças respiratórias, ainda que grande, não apresenta a magnitude apontada em uma análise feita para 88 países apresentada por outros autores. 
LAURENTI, R. Doenças respiratórias como causa de morte no município de São Paulo, SP (Brasil). Rev. Saude públ., S. Paulo, 15:358-63, 1981.

LAURENTI, R. [Respiratory diseases as cause of death in the city of $\mathbf{S}$. Paulo (B:azil) ]. Rev. Saúde públ., S. Paulo, 15.353-68, 1981.

ABSTRACT: Mortality caused by respiratory diseases in the city of S. Paulo (Brazil) was studied. Emphasis is given to the acute respiratory infections and their relative importance as compared to chronic respiratory disease. Mortality data were corrected through research by which additional information was obtained; this correction led to a comparison between the official mortality data and the corrected data. This comparison showed that official statistics, based upon death certificates, did not reflect the magnitude of the problem; that is, acute respiratory infections were overestimated and chronic, underestimated. If the same distortion occurs in other areas of the world, the relative importance of mortality from acute respiratory diseases withing the whole group of respiratory diseases does not have the magnitude stressed by other authors, especially in a study where data from 88 countries wero analysed.

UNITERMS: Respiratory tract diseases, S. Paulo, SP, Brazil. Mortality.

\section{REFERENCIAS BIBLIOGRAFICAS}

1. BULLA, A. \& HITZE, K.L. Acute respiratory infections: a review. Bull. Wld Hlth Org., 56:481-98, 1978.

2. FONSECA, L.A.M. \& LAURENTI, R. A qualidade da certificação médica da ca"sa de morte $\mathrm{cm}$ São Paulo, Rev. Saude públ., S. Paulo, 8:21-9, 1974.

3. GUIMARAES, $C$. et al. Mortalidade de adultos de 15 a 74 anos de idade em São Paulo, Botucatu e săo Manoel (Brasil), 1974/1975. Rev. Saúde públ., S. Paulo, 13 (supl. 2), 1979.

4. LAURENTI, R. Causas múltiplas de morte. Sáo Paulo, 1973. [Tese de Livre-Docência - Faculdade de Saúde Pública da USP].

5. LAURENTI, R. A Investigaçăo Interamericana de Mortalidade na Infancia em Săo Paulo - Brasil. Rev. Saude pribl., S. Paulo, 3:225-9, 1969.
6. MILANESI, M.L. \& LAURENTI, R. O estudo interamericano de mortalidade em Såo Paulo. I - Estado atual da cert1ficação médica da causa de óbito no distrito da Capital. Rev. Ass. med. bras., 10:111-6, 1964.

7. PUFFER, R.R. \& GRIFFITH, G.W. Caracteristicas de la mortalidad urbana. Washington, D.C., Organizacion Panamericana de la Salud, 1968. (OPAS Publ. cient., 151).

8. PUFFER, R.R. \& SERRANO, C.V. Patterns of mortality in childhood. Washington, D.C., Pan American Health Organization, 1973. (PAHO - Scient. publ., 262).

Recebido para publicagão em 06/01/1981

Aprovado para publicacdo em 11/03/1981 